\title{
HF doppler sounder measurements of the ionospheric signatures of small scale ULF waves
}

\author{
L. J. Baddeley, T. K. Yeoman, and D. M. Wright \\ Department of Physics and Astronomy, University of Leicester, University Road, Leicester LE1 7RH, UK
}

Received: 15 November 2004 - Revised: 11 February 2005 - Accepted: 4 April 2005 - Published: 28 July 2005

\begin{abstract}
An HF Doppler sounder, DOPE (DOppler Pulsation Experiment) with three azimuthally-separated propagation paths is used to provide the first statistical examination of small scale-sized, high $m$ waves where a direct measurement of the azimuthal wavenumber $m$, is made in the ionosphere. The study presents 27 events, predominantly in the post-noon sector. The majority of events are Pc4 waves with azimuthal $m$ numbers ranging from -100 to -200 , representing some of the smallest scale waves ever observed in the ionosphere. 4 Pc5 waves are observed in the post-noon sector. The fact that measurements for the wave azimuthal $m$ number and the wave angular frequency are available allows the drift-bounce resonance condition to be used to hypothesise potential particle populations which could drive the waves through either a drift or drift-bounce resonance interaction mechanism. These results are compared with the statistical study presented by Baddeley et al. (2004) which investigated the statistical likelihood of such driving particle populations occurring in the magnetospheric ring current. The combination of these two studies indicates that any wave which requires a possible drift resonance interaction with particles of energies $>60 \mathrm{keV}$, is statistically unlikely to be generated by such a mechanism. The evidence presented in this paper therefore suggests that in the pre-noon sector the drift-bounce resonance mechanism is statistically more likely implying an anti-symmetric standing wave structure while in the post-noon sector both a drift or drift-bounce resonance interaction is statistically possible, indicating both symmetric and anti-symmetric standing mode structures. A case study is also presented investigating simultaneous observations of a ULF wave in ground magnetometer and DOPE data. The event is in the lower $m$ range of the statistical study and displays giant pulsation $(\mathrm{Pg})$ characteristics.
\end{abstract}

Keywords. Ionosphere (Ionosphere-magnetosphere interactions) - Magnetospheric physics (MHD waves and instabilities) - Space plasma physics (Wave-particle interactions)

Correspondence to: L. J. Baddeley

(Lisa.Baddeley@ion.le.ac.uk)

\section{Introduction}

Ultra Low Frequency (ULF) waves can be classified into two basic types with respect to their energy source. The first type, toroidal modes, have an electric field polarized in the radial direction and are characterised by the small magnitude of their effective azimuthal wave numbers $m$, (or equivalently a large scale size in the azimuthal direction). These waves generally have an energy source external to the Earth's magnetosphere and can include such mechanisms as the KelvinHelmholtz instability on the magnetopause, solar wind buffeting or an impulsive increase in solar wind pressure at the front of the magnetopause. The second type of waves, poloidal modes, exhibit electric fields polarized in the azimuthal direction and are conversely characterised by their high magnitude $m$ numbers and small azimuthal scale sizes. These small scale waves are the focus of this paper. One of the generation mechanisms thought to be responsible for these waves is internal to the magnetosphere in the form of wave-particle interactions between standing wave modes along the geomagnetic field and unstable ion populations in the magnetospheric ring current. These interactions lead to perturbations in the electric and magnetic fields in the magnetosphere and ionosphere when free energy is available for wave growth. It has been suggested (e.g. Southwood, 1976; Hughes et al., 1978) that the part of the Ion Distribution Function (IDF) which is able to feed energy into the wave is that where the IDF has a positive gradient, i.e. $\partial \mathrm{f} / \partial \mathrm{W}>0$, where $f$ represents the ion distribution function and $W$ the particle energy.

Such non-Maxwellian IDFs can be created quite commonly by naturally occurring processes in the magnetosphere, such as substorm-associated particle injections. Subsequent to such an injection the ions will gradient-curvature drift westwards where they will, on occasion, satisfy the local drift-bounce resonance condition (Southwood et al., 1969),

$\omega_{\text {wave }}-m_{\text {wave }} \omega_{\text {drift }}=N \omega_{\text {bounce }}$

where $N$ is an integer (usually $0, \pm 1$ ) and $\omega_{\text {wave }}, \omega_{\text {bounce }}$, and $\omega_{d r i f t}$ are the angular frequencies of the wave, the proton bounce, and the proton azimuthal drift, respectively. In the 
above equation $N=0$ Eq. (1) represents drift (drift-bounce) resonance which is characterised by an interaction between an unstable ion population and a fundamental (second harmonic) mode wave structure. Such wave-particle interactions are a process of fundamental importance in collisionless astrophysical plasmas allowing energy from the magnetospheric ring current to enter into and affect the Earth's ionosphere.

The most accurate method of determining the eigenmode and interaction mechanism of a high $m$ wave is through simultaneous ground-satellite observations of the ULF wave and its driving particle population. The paucity of such observations (the authors are aware of only three reported cases: Glassmeier et al., 1999; Wright et al., 2001; Baddeley et al., 2002) has meant that there is much conjecture over the dominance (if one exists) of any particular generation mechanism and eigenmode, particularly in the morning sector. Additionally, in many publications, (e.g. Engebretson et al., 1992; Anderson, 1993; Yeoman and Wright., 2001) the authors do not have simultaneous particle data and thus must speculate as to the nature of the interaction, in many cases proposing that the waves are generated through interactions where free energy from an unstable, but unobserved, particle population in the magnetospheric ring current is fed into the wave mode.

Previous statistical studies of ULF waves have primarily utilised satellite observations (e.g. Arthur and McPherron, 1981; Kokubun et al., 1989; Woch et al. 1990; Takahashi and Anderson, 1992; Cao et al., 1994). The main reason for using satellites was the difficulty in observing such small scale waves both in the ionosphere and on the ground using the instrumentation available at the time. The ionosphere modifies the magnetospheric ULF wave signature, leading to both rotation and attenuation of the magnetic signature of the wave as detected on the ground (e.g. Hughes and Southwood, 1976; Hughes, 1983). This attenuation of the pulsation magnetic perturbation below the ionosphere is proportional to $e^{-k z}$ (e.g. Hughes and Southwood, 1976) where $k$ is the field perpendicular component of the wave number and $z$ is the E-region height. Ground magnetometers work by averaging information from an ionospheric region whose scale size is similar to the height of the E-region. This act of spatial integration introduces problems when observing high $m$ waves which have large phase variations over a limited spatial extent, which means that ground magnetometer data alone are far from optimal for this study. ULF waves are also observed by both VHF and HF radars which provide a higher spatial resolution $(15-45 \mathrm{~km})$ in the E- and F-region ionospheres respectively, although any large scale convection flow that is present can mask the wave signature due to the small velocity perturbation of the wave field.

When considering observations of wave modes in the magnetosphere, satellites traversing an active region, often at great speed, are not always the optimal instrument and as such can often give an incomplete picture of the occurrence of highly localized, small scale waves. Both ground and satellite based studies have focused mainly on identifying the occurrence distribution of each type of wave as classi- fied by frequency and indicating those waves that were driven through wave-particle interactions. It is clear that knowledge of the eigenmode structure of the wave is vital if the interaction mechanism is to be more fully understood.

This paper will present ionospheric observations of high $m$ waves made using the DOPE (DOppler Pulsation Experiment, Wright et al. 1997) HF Doppler sounder. The study is the first to statistically detail only high $m$ waves where a direct measurement of the azimuthal $m$ number is made in the ionosphere. By obtaining measurements of the wave azimuthal $m$ number and angular frequency, the resonance Eq. (1) has been solved. This allows a hypothetical IDF with free energy available to either drive the wave through a drift or drift-bounce resonance interaction to be postulated. The possible dominant eigenmode can then be inferred in a statistical manner when combined with a statistical study of ions in the ring current presented in Baddeley et al. (2004).

In addition to this statistical study, a case study event is also presented where the wave signature is observed both in the ionosphere by the DOPE HF sounder and also on the ground by magnetometers.

\section{Instrumentation}

The DOPE HF Sounder, located near Troms $\varnothing$, Norway (Corrected GeoMagnetic (CGM) lat: $\sim 66^{\circ} \mathrm{N}$, lon: $\sim 105^{\circ} \mathrm{E}$; Lshell location $\sim 6.3$ ) has been operational since May 1995 and is designed to make measurements of the Doppler ionospheric signatures of ULF waves at high latitudes.

The configuration of the DOPE HF sounder is shown in Fig. 1. From May 1995 to October 1998 the system had an initial configuration of one frequency-stable transmitter and receiver with a ground separation of $50 \mathrm{~km}$, marked as path A in Fig. 1. Although this original DOPE system could detect small scale waves in the ionosphere and accurately determine the wave frequency, the system contained only one transmit-receive path which meant that the spatial scale of the wave in azimuth could not be obtained. This paper will detail a statistical study using the new DOPE system which was upgraded in October 1998 from the single path system to a configuration of four frequency-stable transmitters (two at Seljelvnes, Norway, with sounding frequencies of $4.16 \mathrm{MHz}$ and $5.25 \mathrm{MHz}$ giving height-separated reflection points, one at Skibotn, Norway, with a sounding frequency of $5.73 \mathrm{MHz}$ and one at Kilpisjarvi, Finland, with a sounding frequency of $5.26 \mathrm{MHz}$ providing azimuthally separated reflection points). A four-channel receiver system (at Troms $\varnothing$ ) results in ground separations of between 40 and $90 \mathrm{~km}$. These additional new beam paths are shown as paths B and C in Fig. 1. The specifications for this new DOPE system are shown in Table 1. The receiver output is filtered with a cut-off of $15 \mathrm{~Hz}$ at the $3 \mathrm{~dB}$ level, with this Nyquist frequency requiring data sampling at a rate greater than $30 \mathrm{~Hz}$. The data are in fact sampled at the receiver output at $40 \mathrm{~Hz}$ before undergoing a spectral analysis employing a fast Fourier transform (FFT) routine in order to produce a "Doppler trace". The temporal resolution of 
Table 1. Locations of the DOPE transmit, receive and reflection points and the transmit frequencies.

\begin{tabular}{|c|c|c|c|c|c|}
\hline Site & $\begin{array}{l}\text { Geographic } \\
\text { latitude (N) }\end{array}$ & $\begin{array}{c}\text { Geographic } \\
\text { longitude (E) }\end{array}$ & $\begin{array}{l}\text { Magnetic latitude } \\
\text { (AACGM N) }\end{array}$ & $\begin{array}{l}\text { Magnetic longitude } \\
\text { (AACGM E) }\end{array}$ & $\begin{array}{c}\text { Transmitter sounding } \\
\text { frequency }(\mathrm{MHz})\end{array}$ \\
\hline $\begin{array}{l}\text { Receiver } \\
\text { Ramfjordmoen } \\
\text { (EISCAT) (R) }\end{array}$ & $69.59^{\circ}$ & $19.22^{\circ}$ & $66.88^{\circ}$ & $104.49^{\circ}$ & \\
\hline $\begin{array}{l}\text { Transmitter } \\
\text { Seljelvnes (Sj) }\end{array}$ & $69.25^{\circ}$ & $19.43^{\circ}$ & $66.52^{\circ}$ & $104.34^{\circ}$ & $4.16 \& 5.25$ \\
\hline $\begin{array}{l}\text { Transmitter } \\
\text { Skibotn (Sk) }\end{array}$ & $69.35^{\circ}$ & $20.37^{\circ}$ & $66.57^{\circ}$ & $105.15^{\circ}$ & 5.73 \\
\hline $\begin{array}{l}\text { Transmitter } \\
\text { Kilpisjarvi (K) }\end{array}$ & $69.05^{\circ}$ & $20.79^{\circ}$ & $66.23^{\circ}$ & $105.21^{\circ}$ & 5.26 \\
\hline Path & $\begin{array}{l}\text { Path length } \\
\qquad(\mathrm{km})\end{array}$ & $\begin{array}{l}\text { Midpoint latitude } \\
\text { (Geographic N) }\end{array}$ & $\begin{array}{l}\text { Midpoint longitude } \\
\text { (Geographic E) }\end{array}$ & $\begin{array}{l}\text { Midpoint latitude } \\
\text { (AACGM N) }\end{array}$ & $\begin{array}{l}\text { Midpoint longitude } \\
\text { (AACGM E) }\end{array}$ \\
\hline (A) R-Sk & 52 & $69.47^{\circ}$ & $19.80^{\circ}$ & 66.73 & 104.83 \\
\hline (B) R-K & 86 & $69.32^{\circ}$ & $20.02^{\circ}$ & 66.56 & 104.86 \\
\hline (C) R-Sj & 38 & $69.42^{\circ}$ & $19.33^{\circ}$ & 66.71 & 104.42 \\
\hline $\begin{array}{l}\text { Path midpoint } \\
\text { pair }\end{array}$ & $\begin{array}{l}\text { Separation } \\
\quad(\mathrm{km})\end{array}$ & $\begin{array}{l}\text { Bearing from } \\
\text { north }\end{array}$ & $\begin{array}{l}\text { Azimuthal separation } \\
\text { (AACGM longitude) }\end{array}$ & & \\
\hline RSk - RK & 18.5 & $152^{\circ}$ & $0.04^{\circ}$ & & \\
\hline RSk - RSj & 18.9 & $254^{\circ}$ & $0.4^{\circ}$ & & \\
\hline RSj - RK & 29.0 & $112^{\circ}$ & $0.44^{\circ}$ & & \\
\hline
\end{tabular}

these data is $12.8 \mathrm{~s}$ which is the result of consecutive blocks of 512 samples being Fourier analysed. Spectral components with values above some threshold (usually $50 \%$ of the peak value) are included in the Doppler trace and these represent the diagnostic frequency shift. The DOPE data presented in Figs. 2, 3 and 10 of this paper are the peak trace, which represents the peak spectral power of the returned signal in each $12.8 \mathrm{~s}$ data bin. This is necessary in order to reject noise and to create a single-component time-series on which a frequency analysis is possible. The resulting spectral resolution of the data is $0.15 \mathrm{mHz}$. This new system allows direct measurement of the azimuthal $m$ number due to its multi-path configuration.

The Doppler technique utilises the fact that small shifts in the received radio wave frequency can be interpreted as the signature of ionospheric perturbations due to changes in the phase path of the radio wave in the ionosphere. Poole et al. (1988) presented a model in which they identified three mechanisms which could contribute to this Doppler shift: a "magnetic" mechanism, an "advection" mechanism and a "compression" mechanism. The "magnetic" mechanism accounts for changes in the refractive index due to changes in the magnetic field intensity, requiring no bodily movement of electrons. The "advection" mechanism describes a change in refractive index due to a vertical bulk motion of electrons in the ionosphere. This vertical motion is the vertical component of the $\boldsymbol{E} \times \boldsymbol{B}$ plasma drift velocity which arises due to the fact that the oscillating magnetic field lines are not
DOPE Experimental Configuration, 1998 ->

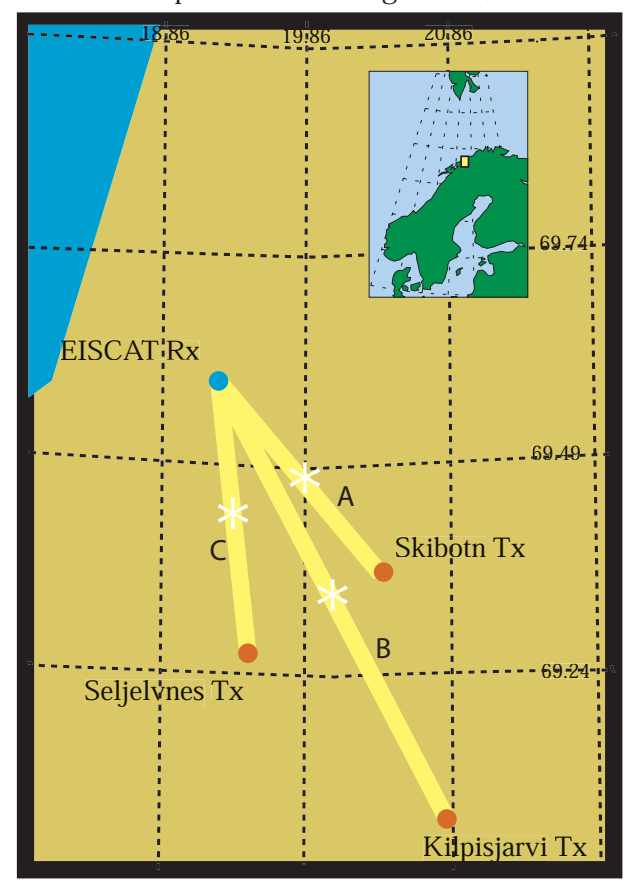

Fig. 1. A schematic of the DOPE (Doppler Pulsation Experiment) HF sounder located in northern Scandinavia. The three beam paths are marked as A, B and C. 

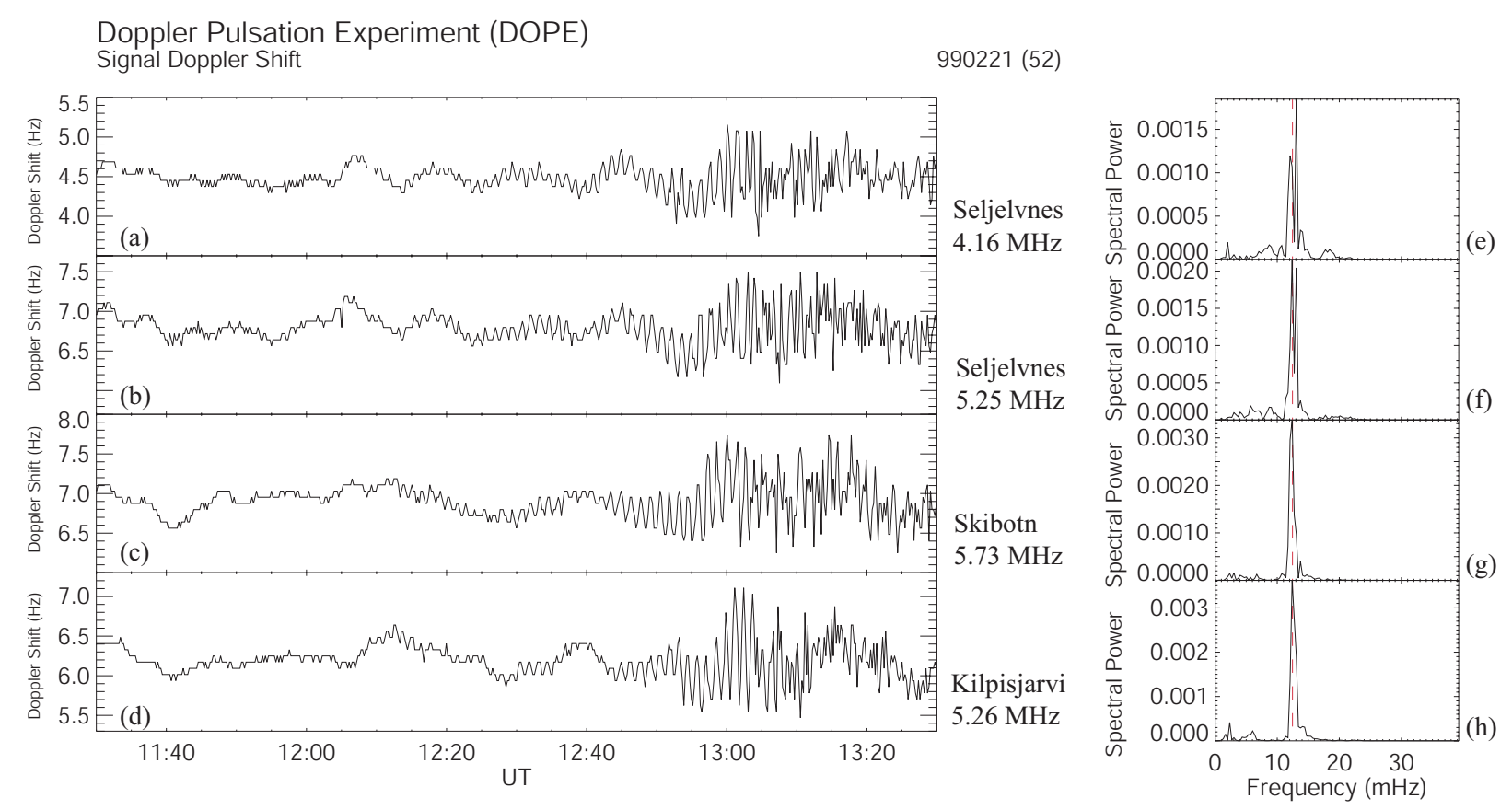

Fig. 2. A Doppler peak trace for each of the four beam paths that make up the DOPE HF sounder measured on the 21 February 1999 . The sounding frequency and station names are indicated to the right of each panel. Panels (e) to (h) indicate the frequency analysis results for each of the Doppler traces in panels (a) to (d) respectively. The time range over which the FFT analysis was made was the same for each Doppler trace (12:10-13:10 UT). The plots are all in the form of frequency (mHz) vs. spectral power.

completely orthogonal to the ground. The "compression" term relates to changes in the refractive index brought about due to changes in the local plasma density caused by propagation in the E-region of a compressional fast mode wave associated with the initial incident Alfvén wave. Subsequent work by Wright et al. (1997), Wright and Yeoman (1999a) and Yeoman et al. (2000) have both discussed this model and compared the results to those observed by DOPE for both large and small scale ULF waves. They concluded that the "advection" mechanism is dominant in the generation of both small and large scale ULF Pc4 and Pc5 waves at high latitudes, as measured by the DOPE sounder. Further studies utilising direct coherent and incoherent radar measurements of the ionospheric electric field of the ULF waves which cause both small (Wright et al. 1998) and large (Wright and Yeoman, 1999b) scale waves in DOPE data have also confirmed the ability of the DOPE sounder to observe MHD waves of magnetospheric origin.

The aforementioned papers and references therein also discuss other phenomena which can cause Doppler shifts in HF signals. Such phenomena include gravity waves, which can be eliminated due to their longer periodicity $(\sim 10 \mathrm{~min})$ and infrasonic waves. The latter can be identified due to the fact that their vertical propagation (Georges, 1973) would result in large phase differences being observed in DOPE's dual-frequency single path beam (beam A). Further modelling by Sutcliffe and Poole $(1989,1990)$ indicate that at F-region reflection heights (such as those investigated in this paper) the phase component from the advection mechanism varies slowly with height, thus allowing elimination of any events which conversely display a large phase difference between the dual-frequency single beam paths. All events presented here have small phase differences between the two propagation paths on DOPE beam A.

\section{Statistical investigation of high $\mathbf{m}$ waves}

\subsection{Statistical database and analysis technique}

This study focuses on 27 pulsation events measured by the multi-path DOPE system between October 1998 and March 2002. During this period the DOPE system measured $\sim 160$ pulsation events in total. The 27 included in this study were extracted if they fulfilled the simple selection criterion that a clear wave signature consisting of at least 10 full wave cycles was observed in all four paths. An example of a wave Doppler peak trace included in the study is shown in Fig. 2. The four panels, (a) to (d), indicate the Doppler trace for each of the paths. The sounding frequency is also shown along with the transmitter station location on the right hand side of each trace. A ULF wave is observed between $\sim 12: 10$ and 13:10 UT.

The data were then passed through an FFT routine to obtain the dominant frequency of the wave. Figure 2, panels (e) to (h) show the frequency analysis results for each of the Doppler peak traces in panels (a) to (d). The time range over which the FFT analysis was undertaken was the same for each Doppler trace (12:10-13:10 UT). The plots are all in 


\section{Doppler Pulsation Experiment (DOPE)}

Signal Doppler Shift

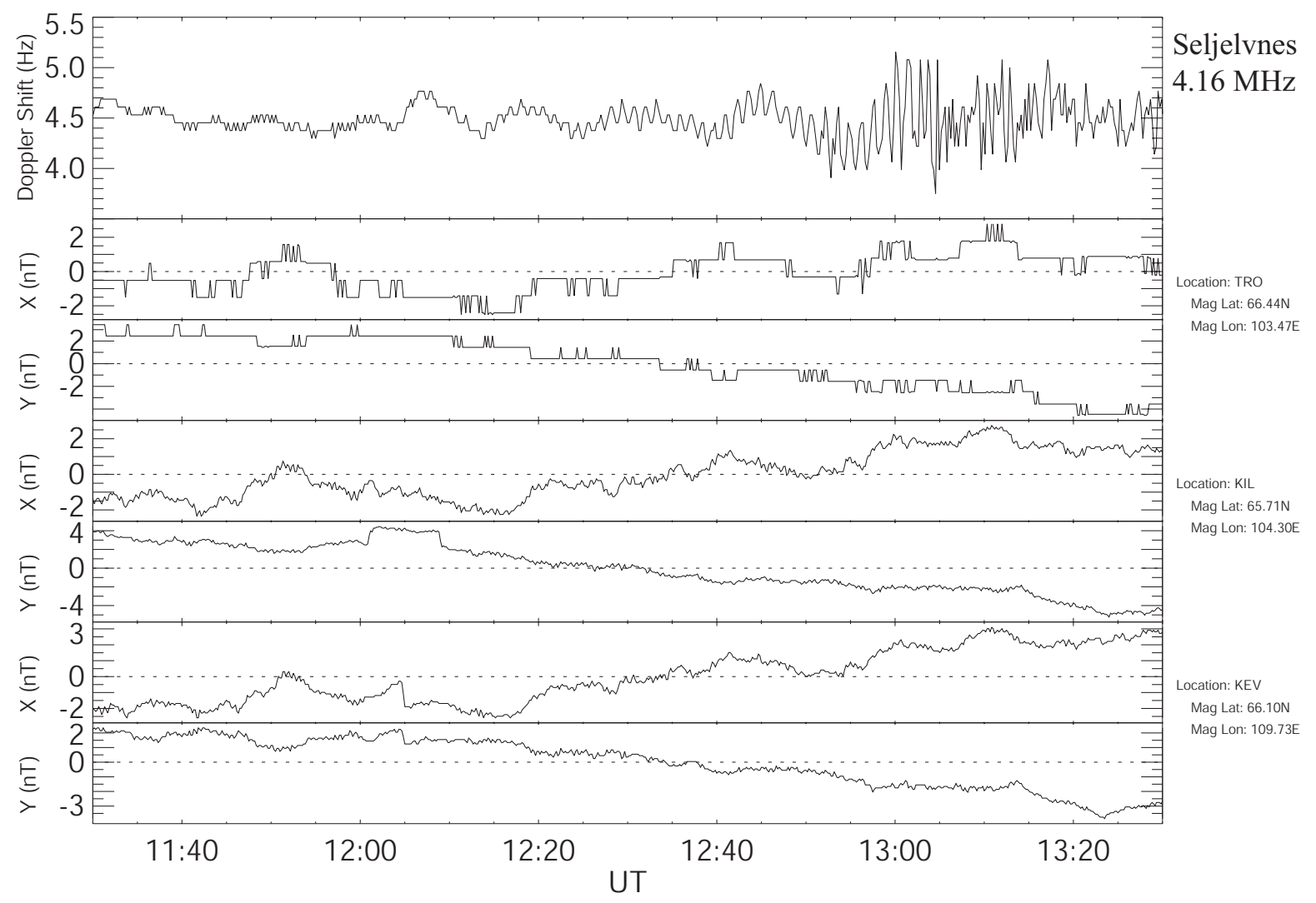

Fig. 3. A DOPE trace (Seljelvnes trace from Fig. 2d) and also magnetometer data from the IMAGE network. This wave event is classified as uncorrelated as there is no magnetic ground signature.

the form of frequency $(\mathrm{mHz})$ vs. spectral power. The dominant peak in all four traces is at $12.5 \pm 0.5 \mathrm{mHz}$, placing the wave in the Pc4 class.

The phase of the wave at the peak spectral power was also obtained for each trace. The first two DOPE traces are from the same transmit-receive path (Seljelvnes to Troms $\varnothing$ ) at different frequencies and hence have different reflection altitudes but similar phase values. By comparing the phase difference between the azimuthally-separated paths the $m$ number can be obtained,

$m=\frac{\Delta \phi}{\Delta \mathrm{L}}$

where $\Delta \phi$ is the change of phase in degrees between two stations located at the same latitude, separated by longitude, $\Delta \mathrm{L}$, in degrees. This calculation was undertaken for various combinations of stations to allow a comparison of the different $m$ values. A calculation was not undertaken between the Skibotn and Kilpisjarvi traces as the latitudinal spacing of their ionospheric reflection points $\left(0.17^{\circ}\right)$ is four times that of their longitudinal spacing $\left(0.04^{\circ}\right)$. In the case of the wave detailed in Fig. 2 calculations indicate an $m$ number of $\sim-170$, the negative sign indicating a westward phase propagation.
A simultaneous spectral analysis was also undertaken on ground magnetometer data to ascertain whether the wave displayed a ground signature. Figure 3 shows a DOPE trace and also magnetometer data from the IMAGE network (International Monitor for Auroral Geomagnetic effects, Lühr 1994) for the same interval. The stations utilised in the study are Troms $\varnothing$ (TRO, CGM lat: $66.64^{\circ}$, long: $102.9^{\circ}$ ), Kevo (KEV ,CGM lat: $66.32^{\circ}$, long: $109.24^{\circ}$ ) and Kilpisjarvi (KIL, CGM lat: $65.88^{\circ}$, long: $103.79^{\circ}$ ) all of which lie at comparable latitudes to the DOPE sounder but covering longitudes from $3^{\circ}$ west to $6^{\circ}$ east of DOPE. Both the $\mathrm{X}$ and $\mathrm{Y}$ components of the magnetometer data for each station are displayed. This wave event is classified an uncorrelated wave (UW) as there is no simultaneous ground signature. The average UT was obtained by averaging the start and end times of all four traces. This was then translated into an MLT location where $\mathrm{MLT}=\mathrm{UT}+2.0$ at the location of DOPE.

For all 27 events the MLT location and UT occurrence was noted and a spectral analysis of the DOPE data and ground magnetometer data was undertaken to accurately determine the dominant frequency component of the wave in the ionosphere and also if the wave displayed a ground signature. Additionally, the relative phase of the wave between DOPE 

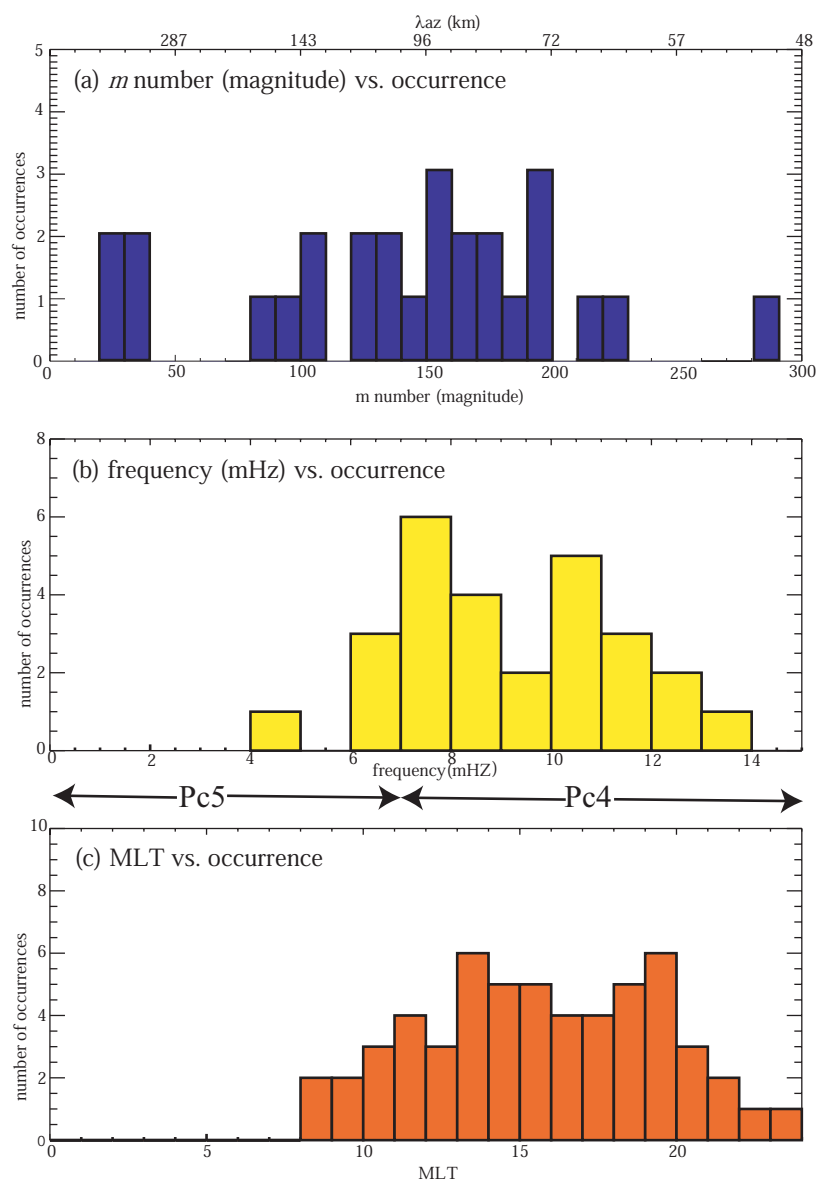

Fig. 4. Occurrence statistics of the 27 pulsation events observed by DOPE.

paths for each event was also examined to obtain the azimuthal $m$ number.

\subsection{Results of statistical study}

All the waves were westward propagating and as such had negative $m$ numbers The DOPE system cannot discern if the waves are radially or azimuthally polarized in nature. However, the fact that they all possess such high $m$ numbers and have an observed vertical component of the $\boldsymbol{E} \times \boldsymbol{B}$ plasma drift velocity implies polarization in the North- South (radial) plane. If by comparison the waves were azimuthally polarized, the geometry of the geomagnetic field in the East-West plane would result in an $\boldsymbol{E} \times \boldsymbol{B}$ plasma drift velocity with a purely horizontal direction vector, making it undetectable to the DOPE system.

The fact that propagation is opposite to the solar wind flow direction in the dusk sector implies that solar wind generation mechanisms, such as the Kelvin Helmholtz instability or solar wind buffeting of the magnetopause, are unlikely. If the waves in the dusk sector had an external generation mechanism then the propagation direction would be expected to possess a phase structure related to the solar wind flow direction. Figure $4 \mathrm{a}$ indicates the $m$ number magnitude dis- tribution of the events as an occurrence histogram. the $m$ numbers range from -20 to -287 for the events. These correspond to equivalent azimuthal ionospheric wavelengths, $\lambda_{a z}$ at Troms $\varnothing$ (geographic latitude $\theta=69.6^{\circ} \mathrm{N}$ ) of $700 \mathrm{~km}$ to $48 \mathrm{~km}$ using

$\lambda_{a z}=\frac{2 \pi R_{E} \cos \theta}{m}$.

The corresponding $\lambda_{a z}$ is shown along the $\mathrm{x}$-axis at the top of the plot in Fig. 4a. The majority of events have $m$ numbers of between -100 and -200 and represent some of the smallest scale waves ever detected in the ionosphere. Figure $4 \mathrm{~b}$ indicates the wave frequency in $\mathrm{mHz}$ as an occurrence histogram, with the data binned in $1 \mathrm{mHz}$ bin sizes. 23 events fall within the Pc4 band $(7-22 \mathrm{mHz})$ and 4 fall within the Pc5 band $(2-7 \mathrm{mHz})$. All four of the Pc5 events occurred in the post-noon sector in the dusk flank between 14 and 19 MLT. Figure $4 \mathrm{c}$ indicates the MLT distribution of the wave events. The histogram represents the cumulative total for the full duration of each event. For example, an event which started at 10:00 MLT and continued till 12:00 MLT would count as a data point in each hourly bin from 10:00 to 12:00 MLT (e.g. 10:00, 11:00 and 12:00 MLT). This method of displaying the MLT location of the wave allows a better understanding of the distribution of events in the magnetosphere. The distribution appears to be centered on the dusk sector with the majority of the wave activity occurring between 13:00 and 19:00 MLT. This distribution will be discussed further in Sect. 5 .

A $\chi^{2}$ test and Pearson's correlation method was applied to the data to establish any relationship between the wave parameters such as frequency and $m$ number. The results for both tests proved inconclusive indicating that more wave events are required to establish if any such correlations exist.

\subsection{Hypothetical driving particle populations}

For each event the drift-bounce resonance, see Eq. (1), can be solved to indicate what the required driving ion population might be, given the azimuthal $m$ number and wave angular frequency, $\omega_{\text {wave }}$.

It is assumed that all the pulsation events have either a fundamental (symmetric, $N=0$ ) or second harmonic (antisymmetric, $N=1$ ) standing wave structure. This assumption is consistent with previous observation of high $m$ waves of this nature observed by both satellites (e.g. Takahashi and McPherron, 1984) and ground instruments (e.g. Yeoman and Wright, 2001). The angular bounce frequency of an interacting particle population can be determined using

$\omega_{\text {bounce }}=\frac{\pi \sqrt{W}}{\sqrt{2 m_{p}} L \mathbf{R}_{\mathbf{E}} T(y)}$,

where $W$ is the proton energy in $\mathrm{eV}, L$ is the proton's L-shell location and the function $\mathrm{T}(\mathrm{y})$ is a function of particle pitch angle $\alpha$, where $\mathrm{T}(\mathrm{y}) \sim(1.3-0.56 \sin \alpha)$, (Glassmeier et al., 
1999; Schulz and Lanzerotti, 1974). The angular drift frequency can be determined using

$\omega_{d r i f t}=-\frac{6 W L P(\alpha)}{B_{S} R_{E}^{2}}+\frac{2 \Psi_{0}(0) L^{3} \sin \varphi}{B_{S} R_{E}^{2}}+\Omega_{E}$,

where, $B_{S}$ is the equatorial surface magnetic field strength and $\varphi$ the azimuth of the particle measured anticlockwise from local midnight. $\mathrm{P}(\alpha)$ takes into account pitch angle effects (Hamlin et al. 1961) with

$P(\alpha) \sim(0.35+0.15 \sin \alpha)$.

$\psi_{0}(0)$ is the Vollard-Stern representation of the convective dawn dusk electric potential, the magnitude of which can be represented as a function of the planetary magnetic index $K_{p}$,

$\psi_{0}(0) \sim 45\left(1-0.159 K_{+} 0.0093 K_{p}^{2}\right)^{-3}$.

For each of the events studied, values for all the parameters in Eqs. (1)-(7), except for the interacting particle energy, $W$ are known. Thus the angular drift frequency, $\omega_{\text {drift }}$ and bounce frequency $\omega_{\text {bounce }}$ of the interacting ion population (in rads $\mathrm{s}^{-1}$ ) as defined in Eqs. (4) and (5) can be obtained as a function of particle energy (in keV) for each event. By plotting the right hand side of Eq. (1) against the left hand side, a solution for both the $N=0$ and $N=1$ cases, as defined in Eq. (1), to be obtained which are purely dependant on the interacting particle population. This method is outlined in greater detail in Baddeley et al. (2002). The results from the wave event described in Fig. 2 are indicated in Fig. 5. The purple shaded area represents the left hand side of the resonance equation, which takes into account the drift angular frequency of the ions and the azimuthal $m$ number and angular frequency of the wave. The yellow shaded areas represent the right hand side of the equation, which deals with contributions from the bounce angular frequency of the ions. The curved yellow shaded area represents the $N=1$ (drift-bounce resonance) solution and the yellow horizontal line running along the $\mathrm{x}$-axis represents the $N=0$ (drift resonance) solution. The spread in the yellow and purple areas represent the maximum error brought about due to uncertainties in the parameters used to obtain values for $\omega_{\text {bounce }}, \omega_{\text {drift }}$ and $\omega_{\text {wave }}$. The azimuthal $m$ number was estimated to be calculated with $10 \%$ accuracy. As discussed in Southwood and Kivelson (1982), drift resonance is expected to occur primarily with particles of larger pitch angles which are confined to the equatorial plane, as the particles then remain in the region of the wave electric field antinode for the greatest time. Conversely, for driftbounce resonance particles of smaller pitch angles, which spend more time out of the equatorial plane are favoured, due to the nature of the electric field structure for the second harmonic. Pitch angle values utilized were, $45^{\circ}$ to $20^{\circ}$ when considering a drift-bounce interaction and $\sim 70^{\circ}$ when considering a drift interaction. The errors arise from the measurement of the angular frequency and $m$ number of the wave and the value for particle pitch angle. A more detailed discussion of the errors involved can be found in Baddeley et al. (2002).

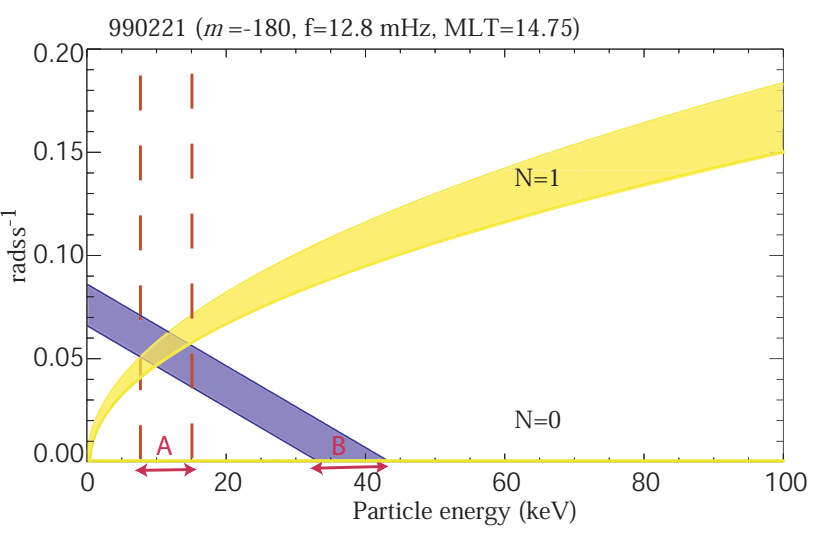

Fig. 5. A graphical representation of the drift-bounce resonance condition (see text for details). It can be seen that the two shaded areas intersect at two locations. If free energy is available to the wave at these interaction energies in the form of a positive gradient in the IDF, then the particle population can provide energy for that wave mode. Particles of energy A represent those which could drive the wave through a drift-bounce resonance interaction while those of energy B could drive the wave through a drift resonance.

The solutions to Eq. (1) for either a drift or drift-bounce resonance interaction are indicated on the plot where the yellow and purple regions intersect, labelled A and B respectively on Fig. 5. If free energy is available to the wave at these energies in the form of a positive gradient region in the IDF then the ion population can drive the wave mode. The wave characteristics are listed at the top of Fig. 5. For the event shown, the analysis of which was detailed in Figs. 2 and 3 , the solution to the resonance equation indicates that the wave could either be a fundamental mode driven through a drift resonance interaction with ions of $33-43 \mathrm{keV}$ or a second harmonic mode driven through a drift-bounce resonance interaction with ions of $7-15 \mathrm{keV}$.

This process was undertaken for all 27 events. The results are shown in Fig. 6, which indicates the MLT location of the event as a function of the possible particle energy in $\mathrm{keV}$ required to drive the pulsation through either a drift or driftbounce resonance interaction. The blue (red) vertical line represents the possible particle energies required to impart energy to the pulsation through a drift (drift-bounce) resonance interaction. Figure 6a indicates the full range of ion energies required for all events and Fig. $6 \mathrm{~b}$ is a more detailed look at ion energy requirements below $60 \mathrm{keV}$ (indicated on Fig. 6a by the green box). For all events higher energy ions are required for a drift resonance than a drift-bounce resonance interaction. There is no obvious relationship between the MLT location of the pulsation and the energy requirements of the interacting ions. The majority of events indicate a driving ion population of energy $<60 \mathrm{keV}$, regardless of the interaction mechanism. The events which require ions of $>100 \mathrm{keV}$ for a drift resonance interaction have the lowest $m$ numbers $(m=-20$ to -35$)$ of the population and 3 out of these 4 events occur in the dusk sector. While the results in Fig. 5 indicate the structure of the IDF which are candidates 


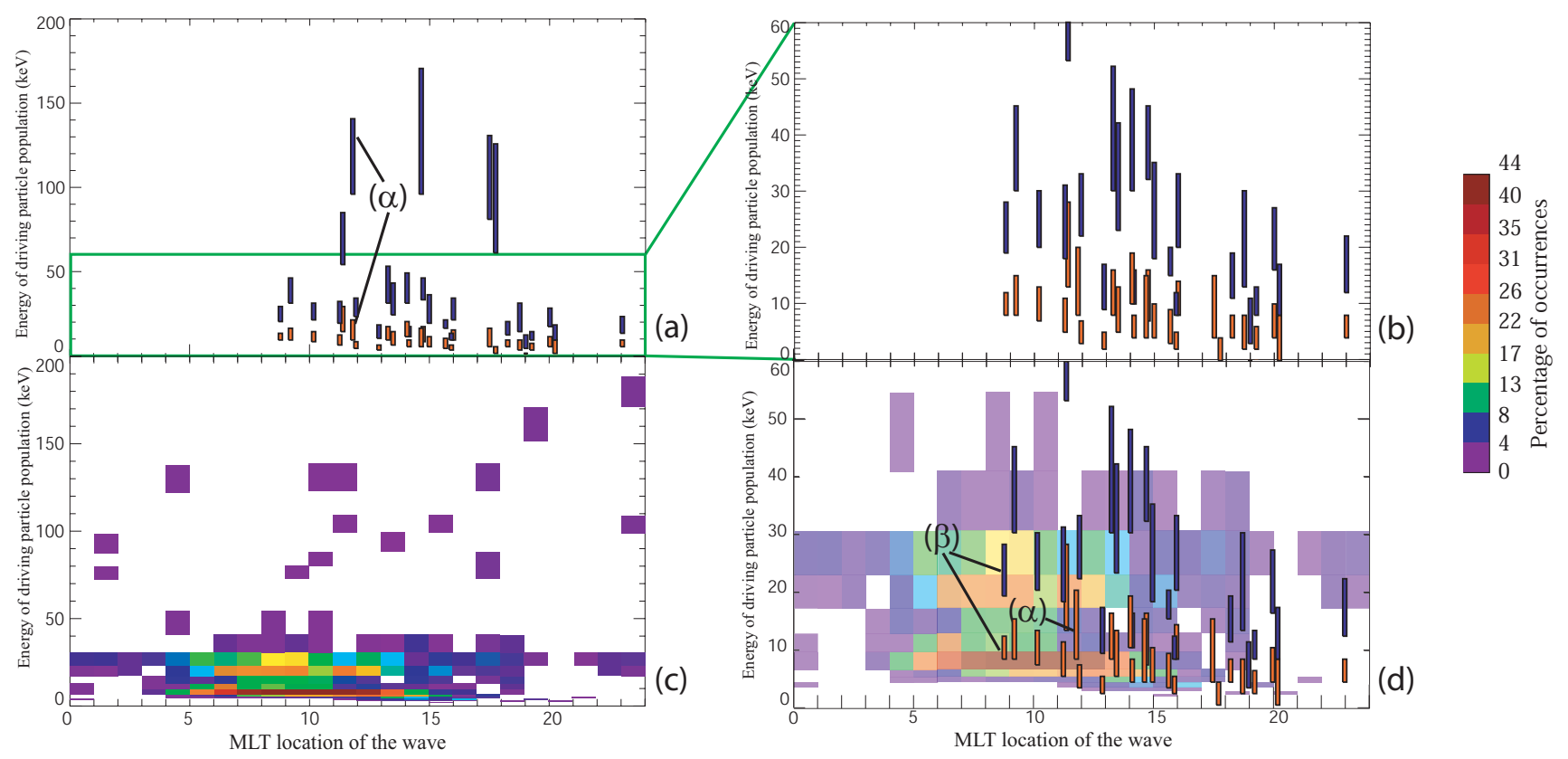

Fig. 6. Inferred particle energy requirements to drive the 27 wave events under study presented with the probability of that particle population existing in the magnetosphere, from the statistical study of Baddeley et al. (2004). Panel (a) indicates the energy of the particles which could provide free energy for each of the pulsation events observed by DOPE as a function of MLT. The possible particle energy for a drift or drift-bounce resonance interaction are indicated in blue and red respectively. Panel (a) indicates all particle energies up to $200 \mathrm{keV}$. Panel (b) is a larger-scale plot of the area indicated by the green box in (a), encompassing particles of up to $60 \mathrm{keV}$. panels (c) and (d) indicate the statistical probability of a particle population of a specific energy existing in the magnetosphere. The figures are colour coded as a function of percentage of the number of IDFs in each MLT bin with the scale indicated on the right hand side of the plots. Panel (d) indicates the particle requirements to drive the wave through a resonant interaction for particles of $<60 \mathrm{keV}$. In this panel the inferred particle energy requirements for wave growth from panel (b) are overplotted for an easier comparison. The specific events (marked $\alpha$ and $\beta$ ) are discussed in the text.

to be driving these waves for either a drift or drift-bounce resonance mechanism, it cannot predict which of the mechanisms is actually driving each wave. Without in situ particle measurements, only a statistical likelihood for the two mechanisms can be demonstrated.

3.4 Comparison with statistical study of driving particle population

Since in situ particle data are not available for the wave events, the results from this statistical study are now combined with the statistical magnetospheric proton distribution function study presented in Baddeley et al. (2004). The statistical study details proton populations at L-shell locations in the magnetosphere which map down to the location of the DOPE HF sounder observations in the ionosphere. This is the first time two such studies have been combined and represents a significant step in determining the importance of energetic ion populations in ULF wave generation.

The particle populations studied in Baddeley et al. (2004) are all in the form of IDFs. This format allows the identification of any possible free energy, which manifests itself as a positive gradient region in the IDF, which could be fed into a resonant wave mode. The database used for the study comprises omnidirectional IDFs measured using the particle detectors on board the Polar spacecraft. The highly elliptical orbit of Polar allows the spacecraft to sample the inner magnetospheric particle population, more specifically, populations located in the ring current thought to drive the ULF waves. Additionally, the precession of the orbit also allows all magnetospheric local times to be sampled. Two instruments were used to measure the IDFs, the TIMAS instrument (Shelley et al., 1995) that measures the lower energy protons from $\sim 0.025 \mathrm{keV}$ to $32 \mathrm{keV}$ and the CAMMICE (Wilken et al., 1992) instrument that extends to higher energies, $1 \mathrm{keV}$ to $328 \mathrm{keV}$. Examples of IDFs from the database are shown in Fig. 7. The plots are in a log-log format with the $\mathrm{x}$-axis indicating the energy of the particles, $W$ from $0.1 \mathrm{keV}$ to $328 \mathrm{keV}$, and the y-axis the corresponding distribution function, $f(W)$. The blue lines on each plot represent data from the TIMAS instrument with the red lines representing data from the CAMMICE (MICS) instrument. Figure 7a illustrates an IDF without a positive gradient region and thus would not be considered as a candidate for a wave energy source. Figure $7 \mathrm{~b}$ indicates an unstable IDF that would be a suitable wave energy source. In the study the IDFs were examined to ascertain the statistical likelyhood of specific particle energies containing free energy, and also how much free energy the populations contained. 
The results from Fig. 7a of Baddeley et al. (2004) have been replotted on the same axis system as Figs. 6a and b to allow a direct comparison with the study presented here. The results are shown in Fig. 6 panels (c) and (d). In panel (c) the particle data covering an energy range of $0-200 \mathrm{keV}$ is shown only with TIMAS data utilised up to $10 \mathrm{keV}$ and then CAMMICE (MICS) data from $10 \mathrm{keV}$ to $200 \mathrm{keV}$. The data bin sizes on the plot are the actual detector bin sizes and these are colour coded to represent the percentage of IDFs with positive gradients in each MLT bin with the scale indicated on the right hand side of the plots. The particle statistical study indicates that the dominant source of unstable ring current IDFs is between 5 and 15 MLT and in the lower energy $(5-40 \mathrm{keV})$ range. The particle population below $60 \mathrm{keV}$ is examined in more detail in Fig. 6d as the majority of the observed waves require particle energies of this order. In this panel the energy requirements of the wave events are superimposed onto the particle data. The combination of these two studies indicates that any wave which requires a possible drift resonance interaction with particles of energies $>60 \mathrm{keV}$, such as the event marked " $\alpha$ " in Figs. 6a and is statistically unlikely to be generated by such a mechanism. This includes the majority of the relatively low $m(\sim-20$ to -50$)$ waves observed. The situation is more complicated for waves which have higher $m$ numbers such as the event marked " $\beta$ " on Fig. 6 d. For events such as this, it would seem likely that a drift or drift-bounce resonance interaction is statistically possible, implying that both symmetric and anti-symmetric eigenmode structures are possible.

\section{Case study - giant pulsation?}

Most of the controversy regarding morning sector waves relates to the standing wave mode and driving particle population of giant "Pg" pulsations. These waves are long lived, highly monochromatic Pc4 oscillations which occur during geomagnetically quiet times (e.g. Chisham, 1996). Pgs are an example of a high $m$ particle-driven ULF wave which may be studied with ground based magnetometers due to their large amplitude although they have also been observed by orbiting satellites. They have been related to drift-bounce resonance mechanisms with both symmetric (e.g. Takahashi et al., 1992; Glassmeier et al., 1999) and anti-symmetric (e.g. Chisham and Orr, 1991) wave modes, hence it is uncertain which (if any) wave-particle interaction responsible for their generation is dominant.

In the statistical database presented here, one of the morning sector waves which occurred does have a simultaneous ground signature. Figure 8a shows a ULF wave which was observed by the DOPE HF sounder on the 19th February 2001 between 08:00 and 11:40 UT (10:00-13:40 MLT). Figures $8 \mathrm{~b}, \mathrm{c}$ and $\mathrm{d}$ show ground magnetometer data from the TRO, KIL and KIR stations. The station names and coordinates are shown to the right of each panel. The $\mathrm{X}$ and $\mathrm{Y}$ components are both shown. The wave trace is clearly seen in the magnetometer data between 10:20 and 11:40 UT (12:20-
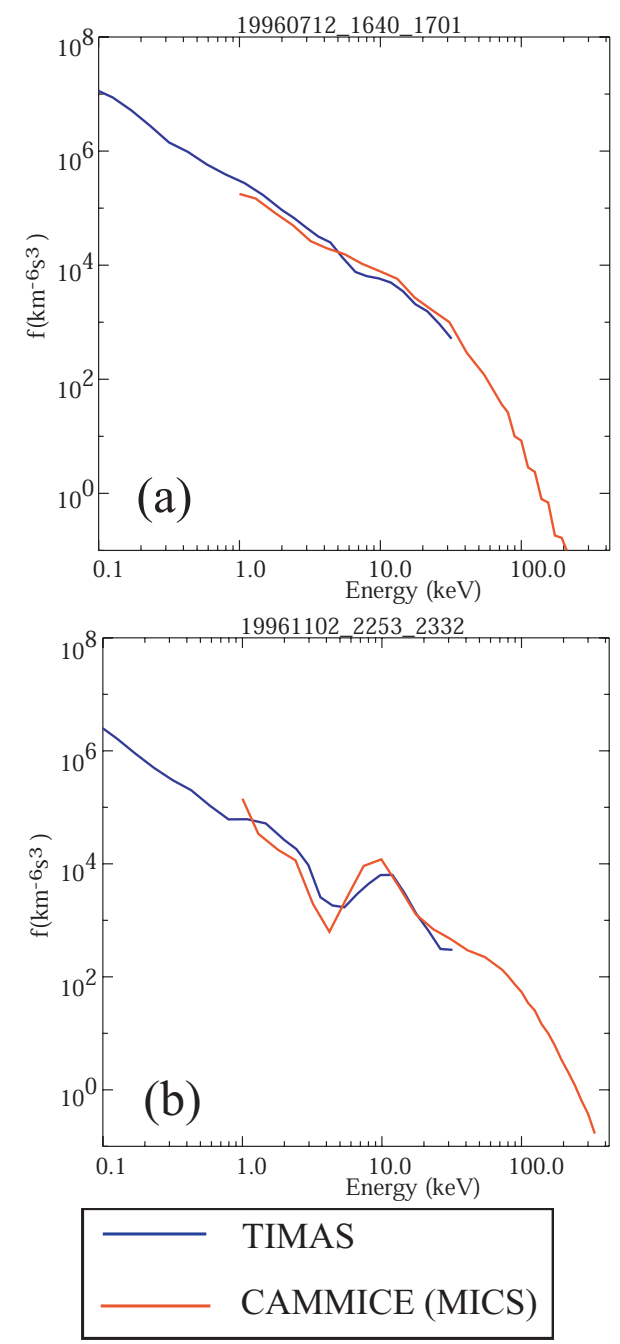

Fig. 7. Example IDFs from the statistical database used in Baddeley et al. (2004). TIMAS data are shown in blue and CAMMICE (MICS) data are shown in red. Panel (a) illustrates an IDF without a positive gradient region and thus would not be considered as a candidate for a wave energy source. Panel (b) indicates an IDF that would be a suitable wave energy source.

13:40 MLT). The panels to the right of the magnetometer and DOPE traces show the result of a FFT analysis undertaken of the DOPE data from 08:00-11:40 UT and the Y component of the magnetometer data from 10:20-11:40 UT. The dominant frequency component is at $\sim 8 \mathrm{mHz}$ for all the traces. The azimuthal $m$ number as measured in the ionosphere by DOPE is $\sim-40$. In comparison, the $m$ number obtained from the ground magnetometer is slightly smaller in magnitude $\sim-30$. This difference in the scale size of the wave between ionospheric and ground measurements was discussed by Ponomarenko et al. (2001) and Ziesolleck et al. (1998) and was attributed to the way in which the measurements are obtained by the two different instruments. More specifically, Ponomarenko et al. (2001) proposed a model which indicated that the two dimensional spatial integration brought 


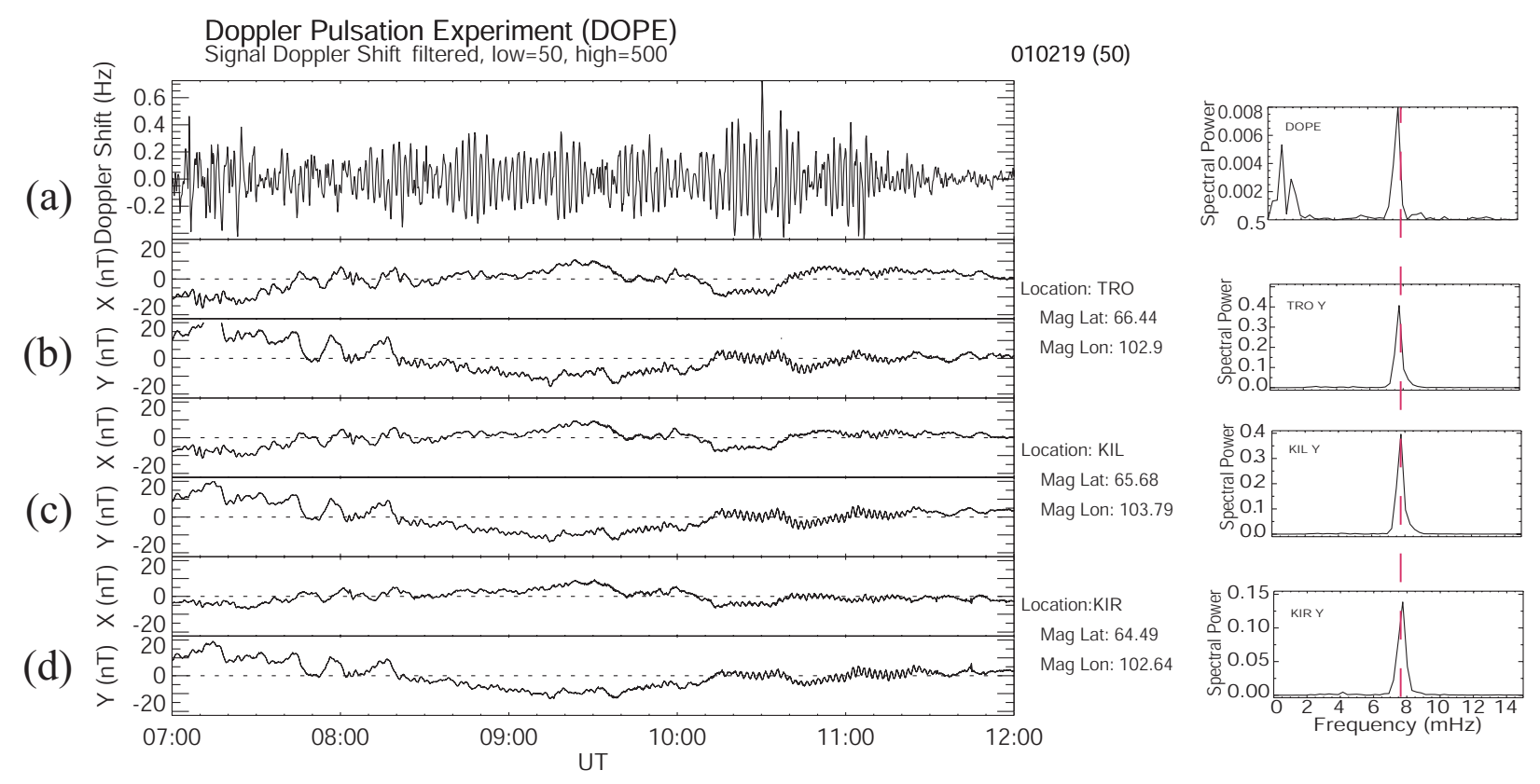

Fig. 8. (a) indicates a Doppler trace from the DOPE HF sounder for the event on the 19th February 2001. (b), (c) and (d) indicate magnetometer data from the TRO, KIL and KIR stations respectively. Panel (a) indicates that the wave was observed by DOPE between 08:00 and 11:40 UT (10:00-13:40 MLT) and panels (b)-(d) indicate the wave observed by the magnetometers between 10:20 and 11:40 UT (12:20 to 13:40 MLT). The panels to the right of the magnetometer and DOPE traces show the result of a FFT analysis undertaken of the DOPE data from 08:00-11:40 UT and the Y component of the magnetometer data from 10:20-11:40 UT. The dominant frequency component is at $\sim 8 \mathrm{mHz}$ for all the traces.

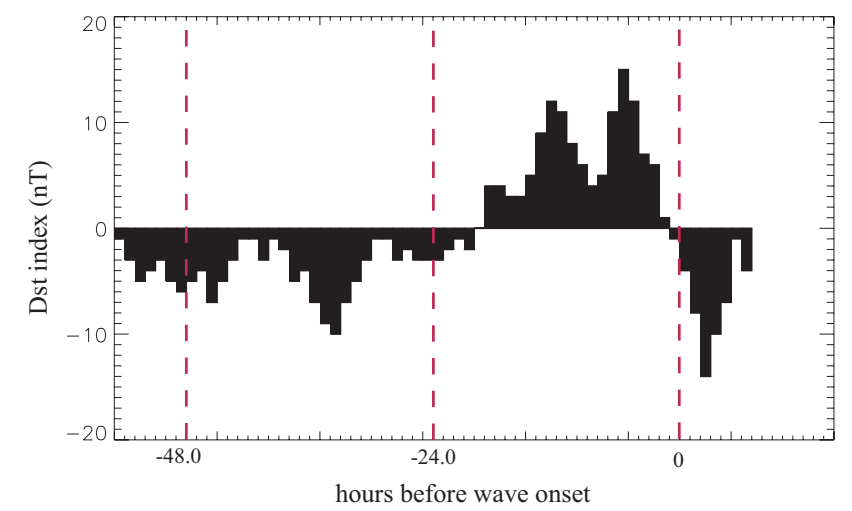

Fig. 9. An analysis of the $\mathrm{D}_{s t}$ index for $\sim 48 \mathrm{~h}$ before the wave observed on the 19 February 2001, presented in Fig. 8.

about due to the finite scale size of the wave in longitude would result in the $m$ value as measured on the ground being smaller than that measured in the ionosphere.

The frequency $(\sim 8 \mathrm{mHz})$ and azimuthal $m$ number $(m \sim-33)$ of the wave are consistent with previous observations of Pgs, although the MLT location is slightly eastwards of the generally accepted location for Pgs. The wave is highly localised in latitude $\left(\sim 3^{\circ}\right.$ and also is dominant in the $\mathrm{Y}$ magnetometer component, indicating the small scale size and radially polarised nature, both traits also consistent with Pgs. Using Eq. (1) and the graphical method outlined in figure 5 it was calculated that the wave could be driven by either $90-140 \mathrm{keV}$ ions or $8-20 \mathrm{keV}$ ions through a drift or drift-bounce interaction respectively. The evidence presented here, both in a case study and statistical nature indicate that it is likely to be a second harmonic standing mode driven through a drift-bounce resonance interaction with 8-20 keV ions. Chisham (1996) proposed that an injection of particles in the tail region followed by a period of reduced geomagnetic activity is required to allow this lower energy driving proton population to traverse to the morning side magnetosphere. To examine this for this event, the $\mathrm{D}_{s t}$ index was also examined for the $48 \mathrm{~h}$ before wave onset. The results are presented in Fig. 9. A value $>-20 \mathrm{nT}$ in the $\mathrm{D}_{s t}$ index is considered geomagnetically quiet. For the entire $48 \mathrm{~h}$ period prior to the wave onset the magnetosphere can be defined as being geomagnetically quiet. Comparatively, the period $24-48 \mathrm{~h}$ before wave onset was the more active. Particle injection process could be occurring in the nightside magnetosphere during this more active time. The magnetosphere then becomes exceptionally quiet during the $24 \mathrm{~h}$ preceding the wave onset, which would provide the necessary conditions for once open drift paths containing newly injected particles to close, allowing the particles to drift round to the dayside magnetosphere in line with the theory of Ozeke and Mann (2001).

What is interesting about this case study is that if ground magnetometer data alone were used to identify this pulsation the extent of the wave both in UT and MLT would have been underestimated by $\sim 2 \mathrm{~h}$. In turn this would imply that 
the amount of energy dissipated into the ionosphere by the wave through Joule heating effects would also be underestimated. The $m$ number as measured by DOPE is consistent throughout the duration of the event (i.e. 08:00-11:40 UT), which implies that the lack of ground signature for the first $2 \mathrm{~h}$ of the wave event is not due to increased levels of attenuation. Figure 8 shows that the amplitude of the wave in the DOPE observations is largest when the wave is also observed in the magnetometer data. This implies that for this event, the amplitude of the wave determines whether or not it is detected by the ground magnetometer. The wave is unlikely to be classed as a Pg due to the fact that it is only evident in the ground magnetometer data for just over $1 \mathrm{~h}$ and the MLT location extends to the post-noon sector. However, it does illustrate the importance of the DOPE HF Doppler sounder in identifying small scale ULF waves and raises the possibility that these types of waves are more prevalent than previously thought.

\section{Discussion}

This paper has presented some of the most accurate ionospheric measurements to date using the multi-path DOPE HF sounder in northern Norway. The study presented 27 events, 7 Pc4 events in the pre-noon sector with 16 Pc4 and 4 Pc5 events in the post-noon sector. The majority of Pc4 waves have azimuthal $m$ numbers ranging from -100 to -200 , representing some of the smallest scale waves ever observed in the ionosphere. This study is now compared to previous studies into high $m$ waves.

Yeoman et al. (2000) detailed observations of 52 high $m$ waves made by the single path DOPE system in the period from 1995-1998, which include observations investigated by Wright and Yeoman (1999a). The observations indicate two clear peaks in occurrence, with a population of afternoon sector waves centred at dusk (18:00 MLT) and a larger population of morning sector waves, centred on 1000 MLT. Yeoman et al. (2000) estimated the expected $m$ values for this morning population using the methods of Allan et al. (1982, 1983) and Yeoman et al. (1992) to be in the range -40 to -100 . In contrast, the study in this paper observed waves predominantly in the post-noon sector. There are several possible explanations for this. Firstly, it is possible that the database of 27 events used in this study is not large enough to indicate this trend. Secondly, it could also be due to more rigorous selection criteria employed in this study, which utilises more Doppler paths than the original study. Ionospheric conditions must also be considered when comparing the two studies. The two studies were undertaken at different points in the solar cycle and the DOPE HF sounder requires an ionosphere of a higher critical frequency than the transmitted signal for reflection to occur, thus during periods when this is not the case no measurements can be made.

Several authors have identified populations of ULF waves which have a symmetric distribution about noon. Takahashi et al. (1985) made multi-spacecraft measurements of ULF waves in the frequency range $1-3 \mathrm{mHz}$, finding $-120<m<-40$, which, in comparison, are at the lower end of the $m$ number range covered in this study.

The wave events presented in this paper were combined with a particle statistical study presented by Baddeley et al. (2004) to determine a possible generation mechanism. There is evidence that the drift-bounce mechanism with 5$40 \mathrm{keV}$ ions is dominant in the morning sector for waves which have $|m|<50$. This is in good agreement with modelling work undertaken by Ozeke and Mann (2001). In their model they proposed that the boundary between open and closed drifting particle orbits, following a nightside particle injection, represents a location where unstable particle distributions can develop. Combining this with magnetospheric plasma density profiles to obtain the fundamental $(N=0)$ and second harmonic $(N=1)$ field line eigenperiods in both the morning and afternoon sectors as a function of L-shell location they concluded that in the morning sector very monochromatic Pc4 waves, highly localised in latitude would be generated through a drift-bounce resonance interaction between a second harmonic standing mode wave and $\sim 10 \mathrm{keV}$ protons.

The results also agree with case studies of morning sector high m waves presented by Baddeley et al. (2002) and Hughes and Grard (1984). In both case studies the waves were concluded to be second harmonic standing wave structures driven though a drift-bounce resonance interaction with $\sim 10 \mathrm{keV}$ and $5 \mathrm{keV}$ protons, respectively.

The majority (20 out of 27 observations) of waves in this statistical study were observed in the dusk sector. The study has also indicated that for the Pc4 waves observed in the dusk flank a drift or drift-bounce resonance interaction was equally possible with ion energies of $<40 \mathrm{keV}$. This is consistent with previous results by Yeoman and Wright (2001) which gave evidence of a high $m$ waves observed in the dusk flank driven through both the $N=0$ drift resonance mechanism and the $N=1$ drift-bounce resonance mechanism with ions of between 37 and $57 \mathrm{keV}$ or 24 and $44 \mathrm{keV}$ respectively. Overall they surmised that an IDF with a positive gradient region located between $\sim 35$ and $45 \mathrm{keV}$ could be providing energy for both waves. The modelling work by Ozeke and Mann (2001) mentioned previously also indicated that the dusk region can support waves driven through drift and driftbounce resonance mechanisms.

Previous studies using both satellite and ground observations, (Kokubun et al., 1989; Anderson et al., 1990; Engebretson et al., 1992 and Lessard et al., 1999) have identified the post-noon sector as the dominant region of the magnetosphere for ULF wave generation. The pulsations fall into two categories; storm time Pc5 waves and quiet time Pc4 waves. Storm time Pc5 pulsations are modes with large compressional components which are observed during geomagnetically active conditions in the dusk flank. Although the driving mechanism is thought to be an instability in the ring current plasma the exact nature of the interaction is not fully understood and as such storm time Pc5 pulsations have been related to both a drift and drift-bounce resonance inter- 
action. Allan et al. $(1982,1983)$ presented observations of storm time Pc5 waves with azimuthal $m$ numbers between -7 and -80 using the STARE (Scandinavian Twin Auroral Radar Experiment, Greenwald et al. 1978) radar. Yeoman et al. (1992) also presented 26 Pc5 events in the dusk sector with $m$ measured to be from -5 to -36 . All the Pc5 waves observed in the study in this paper were also observed in the dusk flank, with 3 of the pulsations possessing $m$ numbers $\sim-25$ and one possessing an $m$ number of $\sim-200$. The events analysed here did not occur during geomagnetically active conditions with $\mathrm{D}_{s t}<-20 \mathrm{nT}$ for $24 \mathrm{~h}$ before and during each interval thus would not be classified as storm time Pc5 pulsations as classified by Allan et al. (1983).

The particle statistical data from Baddeley et al. (2004) suggests that the Pc5 waves could be driven through an interaction with particles of energies $<40 \mathrm{keV}$. By examining Fig. 6d this would imply a drift-bounce resonance interaction for $m \sim-25$. For the Pc5 wave which had an $m$ number $\sim-200$, both a drift and drift-bounce interaction are equally possible. Waves of the type presented in this study have been observed by spacecraft. In the paper by Takahashi et al., 1990, a radially polarized Pc5 wave with a calculated $m$ number of $\sim 100$ was observed using the AMPTE CCE spacecraft. The authors concluded that this wave was a second harmonic wave driven through a drift-bounce resonance interaction with $100 \mathrm{keV}$ protons. The findings of the study presented in this paper indicate that a Pc5 wave with this larger $m$ number is statistically more likely to be generated through an interaction with lower energy particles. This is consistent with the only observation of a ULF wave in the post-noon sector and a simultaneous unstable particle distribution function which was presented by Hughes et al. (1978). The $10 \mathrm{mHz}$ wave was observed at 15:00 LT and judged to be a second harmonic standing mode. Data from the satellite particle detectors also indicated the driving particle population, in the form of an unstable IDF, to be that of $10 \mathrm{keV}$ protons. The wave mode, frequency and driving particle energy suggested a drift-bounce resonance interaction.

The Pc4 waves presented in this study could be a similar population to those described by Engebretson et al. (1992). The authors noted 21 events, the majority of which were radially polarised Pc4 waves which were observed in the postnoon sector during geomagnetically quiet conditions, usually after a magnetic storm. They theorized that the generation mechanism was an interaction between $\sim 100 \mathrm{keV}$ protons and an anti-symmetric standing wave structure. The statistical study presented in this paper has shown that both symmetric and anti-symmetric standing mode structures are equally likely but the driving population would most likely be that of $<40 \mathrm{keV}$ protons.

The case study presented in section 4 detailed a ULF wave with relatively low $m$ number $(m \sim-33)$ when compared to the rest of the waves detailed in the statistical study in this paper. The wave was also observed simultaneously in ground magnetometers and the DOPE HF sounder. The case study indicated quasi-Pg characteristics. This study has shown that the hypothetical interaction mechanism is statistically more likely to be a drift-bounce resonance interaction mechanism with $\sim 10 \mathrm{keV}$ protons. This supports mathematical modelling work by Ozeke and Mann (2001) and observational work by Chisham and Orr (1991) and Wright et al. (2001) which indicates that morning sector pulsations such as Pgs are second harmonic standing mode structures driven by $5-$ $30 \mathrm{keV}$ particles.

\section{Conclusions}

27 pulsation events (comprising of 7 Pc4 pre-noon sector waves and 4 Pc5 and 16 Pc4 post-noon sector waves) observed using the DOPE HF sounder have been presented. The azimuthal $m$ numbers of the Pc4 waves presented in this study are exceptionally high $(m \sim-100$ to -200$)$ representing some of the smallest scale waves ever seen both in the ionosphere and the magnetosphere. Given the fact that the majority of previous statistical studies have focused on satellite observations, the results of this new study utilising ionospheric measurements could represent a significant step in understanding the generation mechanisms and fundamental role ULF waves play in the global magnetospheric system. This study was combined with a statistical study which indicates the occurrence and distribution of the unstable IDFs in the ring current which drive the ULF waves. The key factor in determining which mechanism is statistically the more likely is the energy requirement of this interacting particle population. The majority of free energy is carried by $\sim 5-40 \mathrm{keV}$ ions. The solution to the resonance Eq. (1) thus indicates that for waves with moderately large azimuthal $m$ numbers $(|m|<60)$ a drift-bounce resonance is statistically the more likely. For waves with larger $m$ numbers, both the drift and drift-bounce resonance interactions are possible. When considered alongside the MLT location of the waves in this study this indicates that a drift-bounce resonance is more likely in the pre-noon sector but both drift and drift-bounce resonance interactions are equally likely in the post-noon and dusk sectors.

These observations have indicated that the occurrence of such pulsations could be more common than previously thought on the basis of ground magnetometer, radar and satellite data. As such this implies that the quantity of energy being transported round the magnetospheric cavity and into the ionosphere via wave-particle interactions could have been significantly underestimated.

Acknowledgements. The authors would like to thank the Royal Society and PPARC for funding the DOPE project. L. J. Baddeley is supported by PPARC.

Topical Editor T. Pulkkinen thanks F. Menk, W. Allan, and J. Samson for their help in evaluating this paper.

\section{References}

Allan, W., Poulter, E. M, and Nielsen, E.: STARE observations of a Pc5 pulsation with large azimuthal wave number, J. Geophys. Res. 87, 6163-6172, 1982. 
Allan, W., Poulter, E. M., and Nielsen, E.: Pc5 pulsations associated with ring current proton drifts: STARE radar observations, Planet. Space Sci., 31, 1279-1289, 1983.

Anderson, B. J.: Statistical studies of Pc 3-5 pulsations and their relevance for possible source mechanisms of ULF waves, Ann. Geophys., 11, 128-143, 1993.

Anderson, B. J., Engebretson, M. J., Rounds, S. P., Zanetti, L. J., and Potemra, T. A.: A statistical study of Pc 3-5 pulsations observed by the AMPTE/CCE magnetic fields experiment. 1. Occurrence distributions, J. Geophys. Res., 95, 10 495-10 523, 1990.

Arthur, C. W. and McPherron, R. L.: The statistical character of Pc4 magnetic pulsations at synchronous orbit, J. Geophys. Res., 86, 1325-1334, 1981.

Baddeley, L. J., Yeoman, T. K., Wright, D. M., Davies, J. A., Trattner, K. J, and Roeder, J. A.: Morning sector drift-bounce resonance driven ULF waves observed in artificially induced HF radar backscatter, Ann. Geophys., 20, 1487-1498, 2002,

SRef-ID: 1432-0576/ag/2002-20-1487.

Baddeley, L. J., Yeoman, T. K, Wright, D. M., Trattner, K. J., Kellet, B. J.: Statistical study of unstable particle populations in the global ring current and their relation to the generation of high $m$ ULF waves, Ann. Geophys., 22, 4229-4241, 2004,

SRef-ID: 1432-0576/ag/2004-22-4229.

Cao. M., McPherron, R. L., and Russell, C. T.: Statistical study of ULF wave occurrence in the dayside magnetosphere, J. Geophys. Res.,99, 8731-8753, 1994.

Chisham, G.: Giant pulsations: an explanation for their rarity and occurrence during geomagnetically quiet times, J. Geophys. Res.,101, 24 755-24 763, 1996.

Chisham, G. and Orr, D: Statistical studies of giant pulsations (Pgs): harmonic mode, Planet. Space Sci., 39, 999-1006, 1991.

Engebretson, M. J., Murr, D. L., Erickson, K. N., Strangeway, R. J., Klumpar, D. M., Fuselier, S. A., Zanetti, L. J., and Potemra, T. A.: The spatial extent of radial magnetic pulsation events observed in the dayside near synchronous orbit, J. Geophys. Res., 97, 13 741-13 758, 1992.

Georges, T. M.: Ionospheric effects of atmospheric waves, ESSA tech. Rep., Inst. Environ. Res. (Boulder, Colo.), IER 57-ITSA, 54, 1967.

Glassmeier, K. H., Buchert, S., Motschmann, U., Korth, A., and Pedersen, A.: Concerning the generation of geomagnetic giant pulsations by drift-bounce resonance ring current instabilities, Ann. Geophys., 17, 338-350, 1999,

SRef-ID: 1432-0576/ag/1999-17-338.

Greenwald, R. A., Weiss, W., Nielsen, E., and Thompson, N. R.: STARE: A new radar auroral backscatter experiment in northern Scandinavia, Radio Sci., 13, 1021-1039, 1978.

Hamlin, D. A., Karplus, R., Vik, R. C., and Watson, M.: Mirror and azimuthal drift frequencies for geomagnetically trapped particles, J. Geophys. Res.,66, 1, 1961.

Hughes, W. J.: Hydromagnetic waves in the magnetosphere, in: Solar Terrestrial Physics edited by: Carovillano, R. L., and Forbes, J. M., Reidel, Dordrecht, 1983.

Hughes, W. J. and Grard, R. J. L: A second harmonic geomagnetic field line resonance at the inner edge of the plasma sheet: GEOS 1, ISEE 1 and ISEE 2 observations, J. Geophys. Res., 89, 27552764, 1984.

Hughes, W. J. and Southwood, D. J.: The screening of micropulsation signals by the atmosphere and ionosphere, J. Geophys. Res., 81, 3234-3240, 1976.

Hughes, W. J., Southwood, D. J., Mauk, B., McPherron, R. L.,
Barfield, J. N.: Alfvén waves generated by an inverted plasma energy distribution, Nature, 275, 43-44, 1978.

Kokubun, S., Erickson, K. N., Fritz, T. A., and Mcpherron, R. L.: Local time asymmetry of Pc4-5 pulsations and associated particle modulations at synchronous orbit, J. Geophys. Res., 94, 6607-6625, 1989.

Lessard, M. R., Hudson, M. K., and Lühr, H.: A statistical study of Pc 3-Pc 5 magnetic pulsations observed by the AMPTE/Ion Release Module satellite, J. Geophys. Res., 104, 4523-4538, 1999.

Lühr, H.: The IMAGE magnetometer network, STEP Int. Newslett. 4, 4, 1994.

Ozeke, L. G. and Mann, I. R.: Modeling the properties of high $m$ Alfvén waves driven by the drift-bounce resonance mechanism, J. Geophys. Res., 106, 15 583-15 597, 2001.

Poole, A. W. V., Sutcliffe, P. R., and Walker, A. D. M.: The relationship between ULF geomagnetic pulsations and ionospheric Doppler oscillations: derivation of a model, J. Geophys. Res.,93, 14 656-14 677, 1976.

Ponomarenko, P. V., Waters, C. L., Sciffer, M. D., and Fraser, B. J.: Spatial structure of ULF waves: Comparison of magnetometer and Super Dual Auroral Radar Network data, J. Geophys. Res.,106, 10 509-10 517, 2001.

Schulz, M. and Lanzerotti, L. J.: Particle diffusion in the radiation belts, Springer-Verlag, Berlin, Heidelberg, New York, 1974

Shelley, E. G., Ghielmetti, A. G., Balsiger, H., Black, R. K., Bowles, J. A., Bowman, R. P., Bratschi, O., Burch, J. L., Carlson, C. W., Coker, A. J., Drake, J. F., Fischer, J., Geiss, J., Johnstone, A., Kloza, D. L., Lennartsson, O. W., Magoncelli, A. L., Paschmann, G., Peterson, W. K., Rosenbauer, H., Sanders, T. C., Steinacher, M., Walton, D. M., Whalen, B. A., and Young, D. T.: The Toroidal Imaging Mass-Angle Spectrograph (TIMAS) for the Polar Mission, Space Sci. Rev., 71, 497-530, 1995.

Southwood, D. J.: A general approach to low-frequency instability in the ring current plasma, J. Geophys. Res.,81, 3340-3348, 1976.

Southwood, D. J., Dungey, J. W., and Etherington, R. J.: Bounce resonant interactions between pulsations and trapped particles, Planet. Space Sci., 17, 349-361, 1969.

Sutcliffe, P. R. and Poole, A. W. V.: Ionospheric Doppler and electron velocities in the presence of ULF waves, J. Geophys. Res.,94, 13 505-13 516, 1989.

Sutcliffe, P. R. and Poole, A. W. V.: The relationship between ULF geomagnetic pulsations and ionospheric Doppler oscillations: model predications, Planet. Space Sci.,38, 1581-1593, 1990.

Southwood, D., J. and Kivelson, M. G.: Charged particle behaviour in low-frequency geomagnetic pulsations; Graphical approach, J. Geophys. Res., 87, 1707-1710, 1982.

Takahashi, K. and Anderson, B. J.: Distribution of ULF energy $(f<80 \mathrm{mHz})$ in the inner magnetosphere: A statistical analysis of AMPTE CCE magnetic field data, J. Geophys. Res., 97, 10751-10 773, 1992.

Takahashi, K. and McPherron, R. L.: Standing hydromagnetic oscillations in the magnetosphere, Planet. Space Sci. ,32, 13431359, 1984.

Takahashi, K., Higbie, P. R., and Baker, D. N.: Characteristics of compressional Pc5 waves observed at geostationary orbit, J. Geophys. Res., 90, 1473-1485, 1985.

Takahashi, K., McEntire, R. W., Lui, A. T. Y., and Potemra, T. A.: Ion flux oscillations associated with a radially polarised transverse Pc5 magnetic pulsation, J. Geophys. Res., 95, 3717-3731, 1990. 
Takahashi, K., Sato, N., Warnecke, J., Lühr, H., Spence, H. E., and Tonegawa, Y.: On the standing wave mode of giant pulsations, J. Geophys. Res., 97, 10717-10 732, 1992.

Wilken, B., Weiß, W., Hall, D., Grande, M., Sørass, F., and Fennell, J. F.: Magnetospheric Ion Composition Spectrometer on board the CRRES spacecraft, J. Spacecraft and Rockets, 29, 585-591, 1992.

Woch, J., Kremser, G., and Korth, A.: A comprehensive investigation of compressional ULF waves observed in the ring current, J. Geophys. Res.,95, 15 113-15 132, 1990.

Wright, D. M. and Yeoman, T. K.: High-latitude HF Doppler observations of ULF waves: 2. Waves with small spatial scale sizes, Ann. Geophys., 17, 868-876, 1999a,

SRef-ID: 1432-0576/ag/1999-17-868.

Wright, D. M. and Yeoman, T. K.: CUTLASS observations of a high $-m$ ULF wave and its consequences for the DOPE HF Doppler sounder, Ann. Geophys., 17, 1493-1497, 1999b, SRef-ID: 1432-0576/ag/1999-17-1493.

Wright, D. M., Yeoman, T. K., and Chapman, P. J.: High-latitude HF Doppler observations of ULF waves: 1 . waves with large spatial scale sizes, Ann. Geophys., 15, 1548-1556, 1997,

SRef-ID: 1432-0576/ag/1997-15-1548.
Wright, D. M., Yeoman, T. K., and Davies, J. A.: A comparison of EISCAT and HF Doppler observations of a ULF wave, Ann. Geophys., 16, 1190-1199, 1998,

SRef-ID: 1432-0576/ag/1998-16-1190.

Wright D. M., Yeoman, T. K., Rae, I. J., Storey, J., Stockton-Chalk, A. B., Roeder, J. L., and Trattner, K. J.: Ground-based and Polar spacecraft observations of a giant (Pg) pulsation and its associated source mechanism, J. Geophys. Res., 106, 10 837-10 852, 2001.

Yeoman, T. K. and Wright, D. M.: ULF waves with drift resonance and drift-bounce resonance energy sources as observed in artificially-induced HF radar backscatter, Ann. Geophys., 19, 159-170, 2001,

SRef-ID: 1432-0576/ag/2001-19-159.

Yeoman, T. K., Wright, D. M., Chapman, P. J., and Stockton-Chalk, A. B.: High-latitude observations of ULF waves with large azimuthal wavenumbers, J. Geophys. Res., 105, 5453-5462, 2000.

Yeoman, T. K., Mao Tian, Lester, M., and Jones, T. B.: A study of Pc5 hydromagnetic waves with equatorward phase propagation, Planet. Space Sci., 40, 797-810, 1992.

Ziesolleck, C. W. S., Fenrich, F. E., Samson, J. C., and McDiarmid, D. R.: Pc5 field line resonance frequencies and structure observed by SuperDARN and CANOPUS, J. Geophys. Res., 103, 11771-11 782, 1998. 